\title{
Challenges Fostering Unwillingness to Form Strategic Alliances among Medium-Sized Manufacturing Firms in Tanzania
}

\author{
Kafigi Jeje ${ }^{1}$ \\ ${ }^{1}$ Institute of Accountancy Arusha, Arusha, Tanzania \\ Correspondence: Kafigi Jeje, Institute of Accountancy Arusha, Po Box 2798 Arusha, Tanzania. E-mail: \\ kjeje@iaa.ac.tz
}

Received: September 4, 2014

Accepted: September 30, $2014 \quad$ Online Published: October 16, 2014

doi:10.5430/jms.v5n4p37

URL: http://dx.doi.org/10.5430/jms.v5n4p37

\begin{abstract}
For many years, strategic alliances have attracted the attention of researchers. The most researched area is the challenges facing the development and maintenance of strategic alliances. Most studies on alliance challenges have concentrated on strategic alliances among large firms in developed economies. Little research has been done on the link between these challenges and firms' unwillingness to form strategic alliances. We therefore want to find whether the unwillingness to form strategic alliances among Medium-Sized Enterprises (MEs) from the manufacturing industry in least developed economies like Tanzania are fostered by the prevailing challenges facing strategic alliances. This study examines the views of manufacturing MEs on whether the challenges associated with developing and maintaining strategic alliances discourage them to form strategic alliances. We have adopted both cross-sectional survey design and multistage probability sampling technique to allow the participation of 398 out of 485 CEOs from three zones of Tanzania through questionnaires. A multiple regression analysis reveals the influence of the challenges associated with both cultural incompatibility and risks on firms' unwillingness to form strategic alliances. We recommend that manufacturing MEs in Tanzania must design an effective plan on how to mitigate these challenges before partner selection process begins instead of becoming reluctant to strategic alliance formation due to prevailing challenges.
\end{abstract}

Keywords: strategic alliances, challenges, manufacturing medium-sized firms, multiple regression analysis, Tanzania

\section{Introduction}

Due to economic globalization, strategic alliances between firms are taking place to a great extent (Naumenko, Nikitin, Terziyan, \& Zharko, 2005 ). Strategic alliances are arrangements between independent firms that seek to gain mutual benefits by cooperating in developing, exchanging, sharing or commercializing products, markets, technology and other tangible and intangible assets (Gulati, 1998; Knoke, 2009). To realize the mutual benefits, partners must pay attention to the coordination of their relationship (Kale \& Singh, 2009). A long list of motives and goals is behind strategic alliances (Gulati, 1998). Strategic alliances can be considered as a risk sharing device (Das \& Kumar, 2011) and a source of business performance, competitive advantage and value creation (Todeva \& Knoke, 2005; Ireland, Hitt, \& Vaidyanath, 2002; Das \& Kumar, 2011).

Although strategic alliances are growing at a burgeoning pace particularly in developed economies, least developed countries like Tanzania do not witness a considerable number of these arrangements especially that involve medium-sized manufacturing firms. The challenges that face strategic alliances (see Elmuti \& Kathawala, 2001; Elmuti, Abebe, \& Nicolosi, 2005; Das, 2005; Zineldin \& Dodourova, 2005; Kelly, Schaan, \& Joncas, 2002; Al Khattab, 2012) might be one of the numerous reasons that are behind firms' reluctances to develop and maintain strategic alliances. Instead of listing these challenges, in this paper we intend to know whether these challenges are fostering unwillingness of Tanzania-based manufacturing medium-sized enterprises (MEs) to form strategic alliances or not. We concentrate on manufacturing MEs since they significantly contribute to the economies of most of least developed countries like Tanzania. Strategic alliances would have enabled them to address most of the challenges facing their growth and survival including access to resources such as finance, technology, information, skills and markets. This study links these challenges and the unwillingness of Tanzania-based MEs in forming strategic alliances by specifically finding: 
1. the influence of challenges associated with cultural incompatibility among partnering firms on firms' unwillingness to form strategic alliances

2. the influence of challenges associated with alliance risks on firms' unwillingness to form strategic alliances

This study is organized as follows. From the literature review, we list down various challenges facing strategic alliances (independent variables) and categorize them into two groups. The first group includes challenges associated with cultural incompatibility among partnering firms such as; differences in operating procedures and attitudes, lack of coordination among partnering firms, disparities in objectives and motives, and lack of clear goals and objectives. The second group includes challenges associated with alliance risks such as: performance risk, relational risk/relationship issues, lack of trust and potential for deceit, and unexpected external changes. We therefore establish a linear relationship between the challenges (independent variables) and firms' unwillingness to form strategic alliances (dependent variable) through a multiple regression analysis.

\section{Theoretical Development}

\subsection{The Concept of Organizational Culture}

Defining organizational culture has always been challenging. By referring an organization as a group, we can at least agree that organizational culture contains observed repeated behaviors when people interact, group norms, values, beliefs, philosophy, language, symbols, skills, climate, rituals, shared meanings and a certain set of rules and standard that govern and define an organization (Schuler, Tarique, \& Jackson, 2004; O'Donnell \& Boyle, 2008). These "elements" have to be learned by members of an organization and use them to solve various problems. These problems are referred by Schein $(2004$, p. 17) as "problems of external adaptation and internal integration". Solving them can show how quickly an organization can adapt to the external environment and integrate organization resources, people, and policies internally. These policies are the ones supporting external adaptation (Pool, 2000). Various internal and external changes can be adapted and contained by a stable organization. That is why it can be concluded that an organizational culture shows how stable an organization is (Schein, 2004) and that it can influence organizational performance (Denison, 1984; Denison \& Mishra, 1995; Lunenburg, 2011). It is possible to create an organizational culture that can become a source of competitive advantage. Any organization that links its culture with its business strategy, can experience performance and greater rewards (Gaberman, Devoi, Crump, \& Witjes, 2011). However, that culture must fit the particular business environment (Denison, 1984).

Organizational cultures differ. Every firm has its own culture which defines its operation. Strategic alliances involve two or more partnering firms that share their cultures and try to develop one culture that will be used to solve various problems and challenges facing their alliance as well as executing any emerging opportunity. It is however, challenging to develop a culture that will define their alliance. That is why Elmuti \& Kathawala (2001) and Elmuti, Abebe, \& Nicolosi (2005) assert that partnering firms are likely to face the challenge of cultural incompatibility. Incompatible cultures can result to various challenges associated with maintaining strategic alliances. It is likely that with incompatible cultures, the problem of differences in partnering firms' operating procedures and attitudes will emerge (Elmuti \& Kathawala, 2001). Organizations use different procedures to solve various problems and challenges facing them. These procedures can also define their cultures. We see that since every individual firm has its own culture which defines its operating procedures, it will be difficult to resolve the differences in firms' procedures. We can also find that with incompatible cultures, it is possible that the lack of coordination between partnering organizations may result (Al Khattab, 2012; Elmuti \& Kathawala, 2001). This is resulted by having different personnel from different organizations with different coordination skills. They are also representing their partnering organizations that have different motives and objectives and the possibility of experiencing clear goals and objectives becomes minimal. We can also conclude that one of the challenges associated with maintaining strategic alliances that can be the result of having cultural incompatibility among partnering firms are disparities in motives and objectives (Elmuti, Abebe, \& Nicolosi, 2005; Zineldin \& Dodourova, 2005) and lack of clear goals and objectives (Elmuti \& Kathawala, 2001; Al Khattab, 2012). We urge that, manufacturing firms may not opt for strategic alliances fearing for these challenges and that is why from this context, we can propose the following hypotheses related to cultural incompatibility as:

- There is a positive relationship between differences in operating procedures and attitudes and firms' unwillingness to form strategic alliances

- There is a positive relationship between lack of coordination among partnering firms and firms' unwillingness to form strategic alliances 
- There is a positive relationship between disparities in objectives and motives and firms' unwillingness to form strategic alliances

- There is a positive relationship between lack of clear goals and objectives and firms' unwillingness to form strategic alliances

\subsection{The Concept of Risk and Trust}

Again, defining trust is also challenging. Its definition may depend on several factors including the culture in which trusting individuals, groups or firms exist. But we can agree that in order to achieve organizational goals and objectives, there must be a certain level of joint commitment and cooperation (Puusa \& Tolvanen, 2006). Organisations must be willing for this cooperation. (Hosmer, 1995). Basically, trust encourages cooperation (LaPorta, Lopez-de-Silanes, Shleifer, \& Vishny, 1997; Hosmer, 1995) and it determines the quality of that particular cooperation (Moorman, Zaltman, \& Deshpandé, 1992) and its resulting benefits (Hosmer, 1995) since firms cooperate to seek greater benefits (Cheng \& Fu, 2013). Trust exists when both partners show a sense of reliability, integrity and readiness to protect the interests of each other (Morgan \& Hunt, 1994; Hosmer, 1995). This increases their confidence (Morgan \& Hunt, 1994) and makes them anticipate the best form each other (Hosmer, 1995). Low-trust does not foster interdependence (Lewicki, Tomlinson, \& Gillespie, 2006) and that is why some literatures name "lack of trust and potential for deceit" as one of the main challenges that face strategic alliances (Al Khattab, 2012; Elmuti \& Kathawala, 2001; Elmuti, Abebe, \& Nicolosi, 2005; Das, 2005). The low-trust can be the results of complexities facing partnering organizations. These may include social, behavioural and economical related complexities and technological factors (Msanjila \& Afsarmanesh, 2010). Both internal and external factors can influence the failure of a strategic alliance (Paik, 2005).

We find that trust is related to risk. McAllister (1995, p. 25 ) asserts that "trust enables people to take risks". These risks relate to what their fellow entrusted partners do and intend to do (Kramer, 1999). A partnering firm needs to understand risks involved in strategic alliances (Paik, 2005). These are in most cases relational and performance risks. Relational risks occur when there is lack of commitment from a partnering firm while performance risks occur when firms that truly commit themselves to their alliance face difficulties to achieve their objectives (Das \& Teng, 2001). Sometimes they may fail to achieve their strategic objectives due to unexpected external changes. Strategic alliances face numerous problems when there is a change in strategy and unexpected external changes (Elmuti, Abebe, \& Nicolosi, 2005). We can therefore find that both performance risks (Elmuti \& Kathawala, 2001; Al Khattab, 2012) and relational risks/relationship issues (Elmuti \& Kathawala, 2001; Kelly, Schaan, \& Joncas, 2002) are the main significant challenges facing strategic alliances. In this regard, we conclude that these challenges associated with risks can influence firms' unwillingness to form strategic alliances. We therefore propose the following hypotheses as:

- There is a positive relationship between performance risk and firms' unwillingness to form strategic alliances

- There is a positive relationship between relational risk/relationship issues and firms' unwillingness to form strategic alliances

- There is a positive relationship between lack of trust and potential for deceit among partnering firms and firms' unwillingness to form strategic alliances

- There is a positive relationship between unexpected external changes and firms' unwillingness to form strategic alliances

\section{Methodology}

\subsection{The Study Area}

The study was conducted in all the regions of Tanzania Mainland. The regions were classified into eight geographic zones as follows. Western: (Tabora, Kigoma), Northern: (Kilimanjaro, Tanga, Arusha), Central: (Dodoma, Singida, Manyara), Southern Highlands: (Njombe, Iringa, Ruvuma), Lake: (Kagera, Mwanza, Mara, Shinyanga, Geita, Simiyu), Eastern: (Dar es Salaam, Pwani, Morogoro), Southern: (Lindi, Mtwara) and Southwest Highlands: (Rukwa, Katavi, Mbeya).

\subsection{Target Population}

Manufacturing MEs dealing with food and beverages; textiles and leather; wood and wood products; paper and paper products; chemical, petroleum and plastic products; pottery, glass and non-metallic products; basic metal industries; and fabricated metal products, machinery and equipment took part in this study (National Bureau of Statistics [NBS], 
2013). The Government of the United Republic of Tanzania [URT] (2003) defines MEs as those employing between 50 and 99 people or use capital investment between Tshs 200 million and Tshs800 million. Although manufacturing SMEs are 23,965 (URT, 2012), establishing the total number of manufacturing MEs in Tanzania was challenging. However, we developed a list of manufacturing MEs in Tanzania that was used in the sampling procedure from different sources such as Small Industries Development Organization (SIDO), Tanzania Food and Drugs Authority (TFDA) and Business Registrations and Licensing Agency (BRELA). In this paper, we define manufacturing MEs based on the number of employees.

\subsection{Sample Size}

Our assumption is that about $50 \%$ of the manufacturing MEs operate. This assumption enables us to obtain the optimum number of manufacturing MEs (n) sampled (Cochran, 1977). Other assumptions set the committed error of $4.45 \%$ and $\alpha$ of $5 \%$. The conservative sample size is computed as follows:

$$
\begin{gathered}
\mathrm{n}=\frac{Z_{\alpha / 2}^{2} \mathrm{pq}}{e^{2}} \\
\text { Where } \quad \alpha=0.5 \quad \mathrm{p}=0.5 \quad \mathrm{q}=1-\mathrm{p}=0.5 \quad \mathrm{e}=0.0445 \quad \mathrm{Z}_{\alpha / 2}=1.96
\end{gathered}
$$

The optimum number of manufacturing MEs selected for the sample is 485 .

\subsection{Sampling Procedure}

We adopt both a cross-sectional survey design and a multistage probability sampling technique. We purposively select five zones among the eight zones followed by a random selection of three zones: Eastern, Northern and Lake. We thereafter use systematic sampling to select the required number of manufacturing MEs from each zone (the sample size from Eastern, Northern and Lake zones were 287, 103 and 95 manufacturing MEs respectively) through Probability Proportional to Size (PPS).

\subsection{Data Collection and Analysis}

We used 485 questionnaires to collect data from 485 CEOs representing 485 manufacturing MEs. We were able to receive useful 398 questionnaires ( $82 \%$ response rate). The response rate from each zone was $85 \%, 84.5 \%$ and $70.5 \%$ for Eastern, Northern and Lake Zones respectively. These questionnaires sought information regarding the influence of challenges associated with both cultural incompatibility and alliance risks on manufacturing MEs' unwillingness to form strategic alliances. This influence was predicted by a multiple regression analysis aided by PASW 16 (SPSS 16).

\section{Research Results}

We find that surveyed manufacturing MEs have existed in the manufacturing industry for about 11 years. On average, it shows that they joined the industry in 2003. They also have an average of 60 employees. Firms with both 11 years of industrial experience and at least 60 employees can provide useful information regarding whether the challenges facing strategic alliances influence their unwillingness to enter into strategic alliances or not.

\subsection{Hypothesis Testing}

\subsubsection{Challenges Associated with Cultural Incompatibility}

In determining the influence of challenges associated with cultural incompatibility among partnering firms on firms' unwillingness to form strategic alliances, we have the following hypotheses:

$\mathrm{H}_{0}: \beta_{1}=0$

$\mathrm{H}_{1}: \beta_{1} \neq 0$

$\mathrm{H}_{0}: \beta_{2}=0$

$\mathrm{H}_{1}: \beta_{2} \neq 0$

$\mathrm{H}_{0}: \beta_{3}=0$

$\mathrm{H}_{1}: \beta_{3} \neq 0$

$\mathrm{H}_{0}: \beta_{4}=0$

$\mathrm{H}_{1}: \beta_{4} \neq 0$

Where $\beta_{0}, \beta_{1}, \beta_{2}, \beta_{3}$ and $\beta_{4}$ are coefficients for Constant, $X_{1}, X_{2}, X_{3}$ and $X_{4}$ respectively

$\mathrm{X}_{1}$ denotes "differences in operating procedures and attitudes"

$\mathrm{X}_{2}$ denotes "lack of coordination among partnering firms" 
$\mathrm{X}_{3}$ denotes "disparities in objectives and motives"

$\mathrm{X}_{4}$ denotes "lack of clear goals and objectives"

$\mathrm{Y}$ denotes "firm's unwillingness to form strategic alliances"

CEOs were asked to rate their level of agreement with $\mathrm{X}_{1}, \mathrm{X}_{2}, \mathrm{X}_{3}$ and $\mathrm{X}_{4}$ using a five-point scale (1. Strongly disagree, 2. Disagree, 3. Neither agree nor disagree, 4. Agree, 5. Strongly agree). They were also asked to rate $\mathrm{Y}$ in percentage ( 0 to 100). From these variables, a multiple regression equation is formulated as

$$
Y=\beta_{0}+\beta_{1} X_{1}+\beta_{2} X_{2}+\beta_{3} X_{3}+\beta_{4} X_{4}
$$

Table 1. Multiple regression output for a linear relationship between $Y$ and $X_{1}, X_{2}, X_{3}, X_{4}$

\begin{tabular}{|c|c|c|c|c|c|c|}
\hline \multicolumn{7}{|c|}{ Model Summary } \\
\hline Model & $\mathrm{R}$ & R Square & justed R Square & \multicolumn{3}{|c|}{ Std. Error of the Estimate } \\
\hline$\frac{1}{\text { a. Pred }}$ & $.501^{\mathrm{a}}$ & .251 & .243 & \multicolumn{3}{|c|}{25.14676} \\
\hline \multicolumn{7}{|c|}{ a. Predictors: (Constant), $X_{1}, X_{2}, X_{3}$ and $X_{4}$} \\
\hline \multirow{4}{*}{1} & Model & Sum of Squares & df & Mean Square & $\mathrm{F}$ & Sig. \\
\hline & Regression & 83144.917 & 4 & 20786.229 & 32.871 & $.000^{\mathrm{a}}$ \\
\hline & Residual & 248517.267 & 393 & 632.359 & & \\
\hline & Total & 331662.183 & 397 & & & \\
\hline
\end{tabular}

a. Predictors: (Constant), $\mathrm{X}_{1}, \mathrm{X}_{2}, \mathrm{X}_{3}$ and $\mathrm{X}_{4}$

b. Dependent Variable: $\mathrm{Y}$

Coefficients $^{\mathrm{a}}$

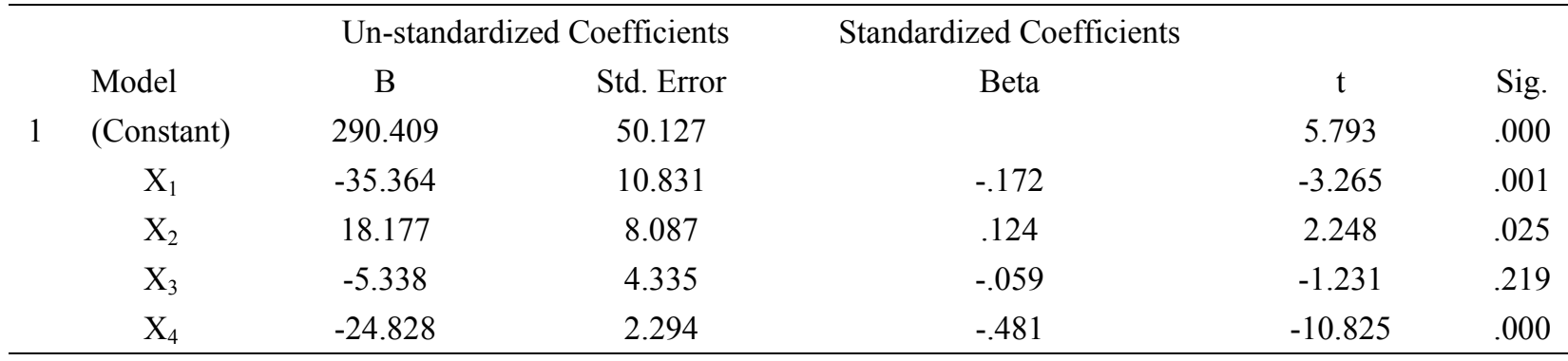

a. Dependent Variable: Y

From Table 1 we see that $X_{1}, X_{2}, X_{3}$ and $X_{4}$ statistically significantly predict $Y, F(4,393)=32.871, p<0.05$. We can also see that $\mathrm{X}_{1}, \mathrm{X}_{2}, \mathrm{X}_{3}$ and $\mathrm{X}_{4}$ explain $25.1 \%$ of the variability of $\mathrm{Y}$. We can therefore set a new regression equation as

$$
\mathrm{Y}=290.409-35.364 \mathrm{X}_{1}+18.177 \mathrm{X}_{2}-5.338 \mathrm{X}_{3}-24.828 \mathrm{X}_{4}
$$

From the first hypothesis $\left(\mathrm{H}_{0}: \beta_{1}=0, \mathrm{H}_{1}: \beta_{1} \neq 0\right)$ we reject $\mathrm{H}_{0}$ since $\beta_{1}(-35.364)$ is statistically significantly different from $0(\mathrm{p}<0.05)$. Regarding the second hypothesis $\left(\mathrm{H}_{0}: \beta_{2}=0, \mathrm{H}_{1}: \beta_{2} \neq 0\right)$ we reject $\mathrm{H}_{0}$ since $\beta_{2}(18.177)$ is statistically significantly different from $0(\mathrm{p}<0.05)$. However, from the third hypothesis $\left(\mathrm{H}_{0}: \beta_{3}=0, \mathrm{H}_{1}: \beta_{3} \neq 0\right)$ we do not reject $\mathrm{H}_{0}$ since $\beta_{3}(-5.338)$ is not statistically significantly different from 0 ( $\left.p>0.05\right)$. Regarding the fourth hypothesis $\left(\mathrm{H}_{0}: \beta_{4}=0, \mathrm{H}_{1}: \beta_{4} \neq 0\right)$ we reject $\mathrm{H}_{0}$ since $\beta_{4}(-24.828)$ is statistically significantly different from 0 $(\mathrm{p}<0.05)$.

\subsubsection{Challenges Associated with Alliance Risks}

In determining the influence of challenges associated with alliance risks on firms' unwillingness to form strategic alliances, we have the following hypotheses;

$\mathrm{H}_{0}: \mathcal{L}_{1}=0$

$\mathrm{H}_{1}: \mathcal{L}_{1} \neq 0$

$\mathrm{H}_{0}: \mathcal{L}_{2}=0$

$\mathrm{H}_{1}: \mathcal{L}_{2} \neq 0$ 
$\mathrm{H}_{0}: \mathcal{L}_{3}=0$

$\mathrm{H}_{1}: \mathcal{L}_{3} \neq 0$

$\mathrm{H}_{0}: \mathcal{L}_{4}=0$

$\mathrm{H}_{1}: \mathcal{L}_{4} \neq 0$

Where $\mathcal{L}_{0}, \mathcal{L}_{1}, \mathcal{L}_{2}, \mathcal{L}_{3}$ and $\mathcal{L}_{4}$ are coefficients for Constant, $\mathrm{X}_{11}, \mathrm{X}_{12}, \mathrm{X}_{13}$ and $\mathrm{X}_{14}$ respectively

$\mathrm{X}_{11}$ denotes "performance risk"

$\mathrm{X}_{12}$ denotes "relational risk/relationship issues"

$\mathrm{X}_{13}$ denotes "lack of trust and potential for deceit"

$\mathrm{X}_{14}$ denotes "unexpected external changes"

Y denotes "firm's unwillingness to form strategic alliances"

CEOs were asked to rate their level of agreement with $\mathrm{X}_{11}, \mathrm{X}_{12}, \mathrm{X}_{13}$ and $\mathrm{X}_{14}$ using a five-point scale (1. Strongly disagree, 2. Disagree, 3. Neither agree nor disagree, 4. Agree, 5. Strongly agree). They were also asked to rate Y in percentage (0 to 100). From these variables, a multiple regression equation is formulated as

$$
\mathrm{Y}=\mathcal{L}_{0}+\mathcal{L}_{1} \mathrm{X}_{11}+\mathcal{L}_{2} \mathrm{X}_{12}+\mathcal{L}_{3} \mathrm{X}_{13}+\mathcal{L}_{4} \mathrm{X}_{14}
$$

Table 2. Multiple regression output for a linear relationship between $Y$ and $X_{11}, X_{12}, X_{13}, X_{14}$

\begin{tabular}{|c|c|c|c|c|c|c|c|}
\hline \multicolumn{8}{|c|}{ Model Summary } \\
\hline Model & $\mathrm{R}$ & R Square & Adju & Square & \multicolumn{3}{|c|}{ Std. Error of the Estimate } \\
\hline 1 & $.398^{\mathrm{a}}$ & .158 & \multicolumn{2}{|c|}{.149} & \multicolumn{3}{|c|}{26.65638} \\
\hline \multicolumn{8}{|c|}{ a. Predictors: (Constant), $X_{11}, X_{12}, X_{13}$ and $X_{14}$} \\
\hline \multicolumn{2}{|c|}{ Model } & & ares & df & Mean Square & $\mathrm{F}$ & Sig. \\
\hline \multirow[t]{3}{*}{1} & ssion & & & 4 & 13102.783 & 18.440 & $.000^{\mathrm{a}}$ \\
\hline & & & & 393 & 710.562 & & \\
\hline & & & & 397 & & & \\
\hline
\end{tabular}

a. Predictors: (Constant), $\mathrm{X}_{11}, \mathrm{X}_{12}, \mathrm{X}_{13}$ and $\mathrm{X}_{14}$

b. Dependent Variable: $\mathrm{Y}$

Coefficients $^{\mathrm{a}}$

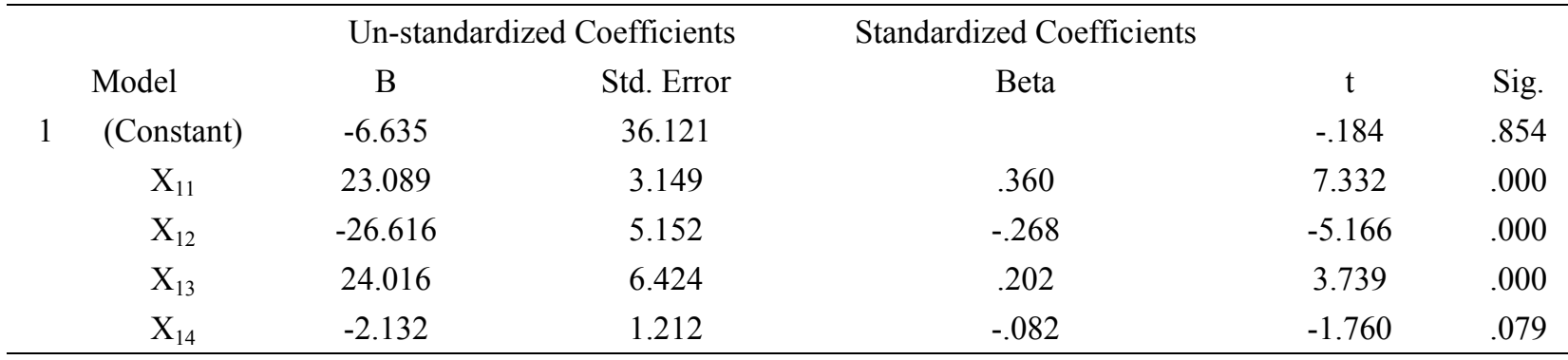

a. Dependent Variable: Y

From Table 2 we see that $X_{11}, X_{12}, X_{13}$ and $X_{14}$ statistically significantly predict $Y, F(4,393)=18.440, p<0.05$. We can also reveal that $\mathrm{X}_{11}, \mathrm{X}_{12}, \mathrm{X}_{13}$ and $\mathrm{X}_{14}$ explain $15.8 \%$ of the variability of $\mathrm{Y}$. The new regression equation becomes;

$$
\mathrm{Y}=-6.635+23.089 \mathrm{X}_{11}-26.616 \mathrm{X}_{12}+24.016 \mathrm{X}_{13}-2.132 \mathrm{X}_{14}
$$

From the first hypothesis $\left(\mathrm{H}_{0}: \mathcal{L}_{1}=0, \mathrm{H}_{1}: \mathcal{L}_{1} \neq 0\right)$ we reject $\mathrm{H}_{0}$ since $\mathcal{L}_{1}(23.089)$ is statistically significantly different from $0(\mathrm{p}<0.05)$. Regarding the second hypothesis $\left(\mathrm{H}_{0}: \mathcal{L}_{2}=0, \mathrm{H}_{1}: \mathcal{L}_{2} \neq 0\right)$ we reject $\mathrm{H}_{0}$ since $\mathcal{L}_{2}(-26.616)$ is statistically significantly different from $0(\mathrm{p}<0.05)$. Also, from the third hypothesis $\left(\mathrm{H}_{0}: \mathcal{L}_{3}=0, \mathrm{H}_{1}\right.$ : $\left.\mathcal{L}_{3} \neq 0\right)$ we reject $\mathrm{H}_{0}$ since $\mathcal{L}_{3}(24.016)$ is statistically significantly different from $0(\mathrm{p}<0.05)$. However, in testing the fourth hypothesis $\left(\mathrm{H}_{0}: \mathcal{L}_{3}=0, \mathrm{H}_{1}: \mathcal{L}_{3} \neq 0\right)$ we do not reject $\mathrm{H}_{0}$ since $\mathcal{L}_{4}(-2.132)$ is not statistically significantly different from $0(\mathrm{p}>0.05)$. 


\section{Discussion}

Some of the challenges associated with cultural incompatibility among partnering firms foster MEs' unwillingness to form strategic alliances. These include differences in operating procedures and attitudes, lack of coordination among partnering firms, and lack of clear goals and objectives. The challenge of "disparities in objectives and motives" does not predict firms' unwillingness to form strategic alliances. This might be due to the fact that firms expect different motives and objectives from each partner and it is simple for them to resolve these differences before and after forming strategic alliances. One of the strategies of settling these differences in motives and objectives is to set a unified alliance objective and goal. However, it might be difficult to settle this challenge since MEs expect that their alliances will lack clear goals and objectives. Lack of coordination among partnering firms is another challenge. MEs are reluctant to form strategic alliances fearing the difficulties in maintaining successful strategic alliances associated with poor coordination. Clear goals and objectives could be developed by partnering MEs if there would be coordination among them. Lack of coordination can also result to difficulties in handling the differences in operating procedures and attitudes. However, as we have seen, since MEs point out cultural incompatibility as a key challenge that would face their alliances, we can agree that different corporate cultures may result to differences in operating procedures and attitudes. Having a unified culture, differences in operating procedures and attitudes will be resolved and hence smooth coordination among partnering MEs as well as clear alliance goals and objectives.

We also see that among the four challenges associated with alliance risks used in this study to predict firms' unwillingness to form strategic alliances, only one does not exert any influence. This is "unexpected external changes". This might be due to the fact that firms find difficulties to pre-identify unexpected external changes. These changes usually come into different forms and intensity. Once in an alliance, firms can be able to solve some unexpected external changes and face difficulties to solve some of them. These changes can include competition, changes of political, legal, economic, social and physical environments. After uniting, firms expect an increased strength which can curb this challenge. However, MEs do face these unexpected external changes even when they are not in strategic alliances. On the contrary, performance risk, relational risk, lack of trust and potential for deceit among partnering firms foster firms' reluctance to develop and maintain strategic alliances.

MEs believe that their performances will be endangered once they collaborate. This challenge might prevail particularly when firms already have fear of combining different goals, objectives, procedures, attitudes and cultures in carrying out strategic alliances' business operations as shown above. This combination might produce a vague and complex system which will halt performance. Relationship issues/relational risks are also the challenges that foster MEs' unwillingness to form strategic alliances. Once an alliance faces relationship risks, its performance might be endangered. Relationship problems might also be influenced by lack of trust and potential for deceit, lack of coordination, and differences in operating procedures, attitudes and cultures. These factors when combined can intensively halt the performance of a strategic alliance and hence collapse. However, outweighing their existence can result to effective alliances and influence MEs to opt for strategic alliances.

\section{Conclusion}

This study is geared towards finding the influence of both challenges associated with cultural incompatibility among partnering firms and those associated with alliance risks on firms' unwillingness to form strategic alliances. Although these challenges are found to be powerful in fostering MEs not to opt for strategic alliances in Tanzania, we find that disparities in partnering firms' objectives and motives cannot influence firms' reluctance to form strategic alliance. We also find that unexpected external changes cannot influence manufacturing MEs' unwillingness to form strategic alliance. We therefore conclude that unless differences in operating procedures and attitudes, lack of coordination among partnering firms, lack of clear goals and objectives, performance risk, relational risk, and lack of trust and potential for deceit among partnering firms are mitigated, MEs in Tanzania will not opt for strategic alliances. Prospective partnering firms should therefore design a comprehensive and effective operation framework before forming any strategic alliance. This framework should be set to offset risks associated with strategic alliances and curb the challenges that are the results of differences in partners' cultures. The framework should also find ways on how to place trust among strategic partners. Since "prevention is better than cure", we urge that manufacturing MEs should also find ways to solve these challenges before they make final decisions that lead to strategic alliances with other firms. This strategy will help them to become willing to form strategic alliances; imperative arrangements for their growth and survival chances.

\section{Acknowledgements}

I express my gratitude to Maagi Mapesi Thomas and Faraja Kristomus for their useful comments and suggestions. 


\section{References}

Al Khattab, S. A. (2012). Marketing Strategic Alliances:The Hotel Sector in Jordan. International Journal of Business and Management, VII(9), 222-232. http://dx.doi.org/10.5539/ijbm.v7n9p222

Cheng, J., \& Fu, Y. (2013). Inter-organizational Relationships and Knowledge Sharing through the Relationship and Institutional Orientations in Supply Chains. International Journal of Information Management, XXXIII, 473-484.

Cochran, W. G. (1977). Sampling Techniques (3rd ed.). New York: John Wiley \& Sons.

Das, T. K. (2005). Deceitful Behaviors of Alliance Partners:Potential and Prevention. Management Decision, XLIII(5), 706-719. http://dx.doi.org/10.1108/00251740510597725

Das, T. K., \& Kumar, R. (2011). Regulatory Focus and Opportunism in the Alliance Development Process. Journal of Management, XXXVII(3), 682-708. http://dx.doi.org/10.1177/0149206309356325

Das, T. K., \& Teng, B. (2001). A Risk Perception Model of Alliance Structuring. Journal of International Management, VII, 1-29. http://dx.doi.org/10.1016/S1075-4253(00)00037-5

Denison, D. R. (1984). Bringing Corporate Culture to the Bottom Line. Organizational Dynamics, XIII (2), 5-22.

Denison, D. R., \& Mishra, A. K. (1995). Toward a Theory of Organizational Culture and Effectiveness. Organization Science, VI(2), 204-223.

Elmuti, D., Abebe, M., \& Nicolosi, M. (2005). An Overview of Strategic Alliances Between Universities and Corporations. The Journal of Workplace Learning, XVII(1/2), 115-129. http://dx.doi.org/10.1108/13665620510574504

Elmuti, D., \& Kathawala, Y. (2001). An Overview of Strategic Alliances. Management Decision, XXXIX(3), $205-217$. http://dx.doi.org/10.1108/EUM0000000005452

Gaberman, I., Devoi, I., Crump, K., \& Witjes, M. (2011). Demystifying Corporate Culture:Why People Do What They Do. Chicago, Illinois: A.T Kearney.

Gulati, R. (1998). Alliances and Networks. Strategic Management Journal, XIX(4), $293-317$. http://dx.doi.org/10.1002/(SICI)1097-0266(199804)19:4<293::AID-SMJ982>3.0.CO;2-M

Hosmer, L. T. (1995). Trust:The Connecting Link between Organizational Theory and Philosophical Ethics. The Academy of Management Review, XX(2), 379-403. http://dx.doi.org/10.5465/AMR.1995.9507312923

Ireland, R. D., Hitt, M. A., \& Vaidyanath, D. (2002). Alliance Management as a Source of Competitive Advantage. Journal of Management, XXVIII(3), 413-446. http://dx.doi.org/10.1177/014920630202800308

Kale, P., \& Singh, H. (2009). Managing Strategic Alliances:What Do We KnowNow, and Where Do We Go From Here? Academy of Management $\quad$ Perspectives, $\quad$ XXXIII(3), http://dx.doi.org/10.5465/AMP.2009.43479263

Kelly, M. J., Schaan, J., \& Joncas, H. (2002). Managing Alliance Relationships:Key Challenges in the Early Stages of Collaboration. R\&D Management, XXXII(1), 11-22. http://dx.doi.org/10.1111/1467-9310.00235

Knoke, D. (2009). Playing Well Together:Creating Corporate Social Capital in Strategic Alliance Networks. American Behavioral Scientist, LII(12), 1690-1708. http://dx.doi.org/10.1177/0002764209331533

Kramer, R. M. (1999). Trust and Distrust in Organizations:Emerging Perspectives, Enduring Questions. Annual Review of Psychology, L, 569-598.

LaPorta, R., Lopez-de-Silanes, F., Shleifer, A., \& Vishny, R. W. (1997). Trust in Large Organizations. American Economic Review Papers and Proceedings, LXXXVII(2), 333-338.

Lewicki, R. J., Tomlinson, E. C., \& Gillespie, N. (2006). Models of Interpersonal Trust Development:Theoretical Approaches, Empirical Evidence, and Future Directions. Journal of Management, XXXII(6), 991-1022. http://dx.doi.org/10.1177/0149206306294405

Lunenburg, F. C. (2011). Organizational Culture-Performance Relationships:Views of Excellence and Theory Z. National Forum of Educational Administration and Supervision Journal, XXIX(4), 1-10.

McAllister, D. J. (1995). Affect- and Cognition-Based Trust as Foundations for Interpersonal Cooperation in Organizations. Academy of Management Journal, XXXVIII(1), 24-59. http://dx.doi.org/10.2307/256727 
Moorman, C., Zaltman, G., \& Deshpandé, R. (1992). Relationships between Providers and Users of Market Research:The Dynamics of Trust within and between Organizations. Journal of Marketing Research, XXIX(3), 314-328.

Morgan, R. M., \& Hunt, S. D. (1994). The Commitment-Trust Theory of Relationship Marketing. The Journal of Marketing, LVIII(3), 20-38. http://dx.doi.org/10.2307/1252308

Msanjila, S. S., \& Afsarmanesh, H. (2010). FETR:A Framework to Establish Trust Relationships among Organizations in VBEs. Journal of Intelligent Manufacturing, XXI(3), 251-265.

Naumenko, A., Nikitin, S., Terziyan, V., \& Zharko, A. (2005 ). Strategic Industrial Alliances in Paper Industry:XML- vs Ontology-Based Integration Platforms. The Learning Organization, XII(5), 492-514. http://dx.doi.org/10.1108/09696470510611438

NBS. (2013). Quarterly Production of Industrial Commodities:2004-2012. Dar es Salaam:National Bureau of Statistics, United Republic of Tanzania.

O’Donnell, O., \& Boyle, R. (2008). Understanding and Managing Organisational Culture. Dublin, Ireland: Institute of Public Administration.

Paik, Y. (2005). Risk Management of Strategic Alliances and Acquisitions between Western MNCs and Companies in Central Europe. Thunderbird International Business Review, XLVII(4), 489-511. http://dx.doi.org/10.1002/tie.20064

Pool, S. W. (2000). Organizational Culture and its Relationship between Job Tension in Measuring Outcomes among Business Executives. Journal of Management Development, XIX(1), 32-49. http://dx.doi.org/10.1108/02621710010308144

Puusa, A., \& Tolvanen, U. (2006). Organizational Identity and Trust. Electronic Journal of Business Ethics and Organization Studies, XI(2), 29-33.

Schein, E. H. (2004). Organizational Culture and Leadership (3rd ed.). San Francisco: John Wiley \& Sons, Inc.

Schuler, R. S., Tarique, I., \& Jackson, S. E. (2004). Managing Human Resources in Cross-Border Alliances. In Advances in Mergers and Acquisitions (Vol. III, pp. 103-129). Elsevier Ltd.

Todeva, E., \& Knoke, D. (2005). Strategic Alliances and Models of Collaboration. Management Decision, XLIII(1), 123-148. http://dx.doi.org/10.1108/00251740510572533

URT. (2003). Small and Medium Enterprise Development Policy. Dar es Salaam: Ministry of Industry and Trade-The Government of the United Republic of Tanzania.

URT. (2012). National Baseline Survey Report for Micro, Small, and Medium Enterprises in Tanzania. United Republic of Tanzania: Ministry of Industry and Trade (MIT) and Financial Sector Deepening Trust (FSDT).

Zineldin, M., \& Dodourova, M. (2005). Motivation, Achievements and Failure of Strategic Alliances:The Case of Swedish Auto-Manufacturers in Russia. European Business Review, XVII(5), 460-470. http://dx.doi.org/10.1108/09555340510620357 